\title{
Gang Reengagement Intentions among Incarcerated Serious Juvenile Offenders
}

\author{
Daniel Boduszek, ${ }^{1}$ Katie Dhingra, ${ }^{2}$ and Alexander Hirschfield ${ }^{1}$ \\ ${ }^{1}$ Department of Behavioural and Social Sciences, University of Huddersfield, Huddersfield HD1 3DH, UK \\ ${ }^{2}$ Manchester Metropolitan University, Manchester M15 6GX, UK
}

Correspondence should be addressed to Daniel Boduszek; d.boduszek@hud.ac.uk

Received 3 September 2014; Revised 13 December 2014; Accepted 16 December 2014

Academic Editor: Xiaojin Chen

Copyright (C) 2015 Daniel Boduszek et al. This is an open access article distributed under the Creative Commons Attribution License, which permits unrestricted use, distribution, and reproduction in any medium, provided the original work is properly cited.

\begin{abstract}
Research examining the factors that precipitate gang membership has contributed substantially to our understanding of gangs and gang-related activity, yet we know little about the factors influencing intentions to rejoin a gang after having being incarcerated. This study examines the relationship between gang characteristics, number of incarcerated friends, and family characteristics and gang reengagement intentions, while controlling for ethnicity. Participants were 206 male serious juvenile offenders interviewed as part of the Pathways to Desistance Study. The model explained between 35\% and 47\% of variance in gang reengagement intentions. However, only three variables made a unique statistically significant contribution to the model (punishment if gang rules are broken, importance of gang membership, and moral disengagement), with the strongest predictor being importance of gang membership. The results suggest that challenging young offenders' perceptions about the importance of gang membership might be particularly effective in reducing gang reengagement intentions after incarceration.
\end{abstract}

\section{Introduction}

Research to date has largely focused on identifying the factors associated with initial gang involvement and the criminological outcomes of gang membership [1]. Although past research has established that self-reported intentions to remain in a gang is a correlate of continued gang involvement, factors associated with the intention to rejoin a gang after being incarcerated, however, have not been studied systematically. Intentions are self-instructions to perform particular behaviours or to obtain certain outcomes [2] and are, according to the theory of planned behaviour [3], the theory of reasoned action $[4,5]$, and the model of interpersonal behaviour [2], the most immediate and important determinants of behaviour. Bagozzi [6] further suggested that intentions or self-predictions were superior predictors of behaviour than desires, attitudes, subjective norm, and perceived control over behaviour. Given the robust association between gang membership and delinquency [1], the detrimental effects of prolonged gang membership (e.g., increased violent behaviour, precocious transitions, violence victimization, suicide ideation, and unemployment), and the potential for these negative effects to accumulate over time (e.g., $[7,8]$ ), it is imperative that researchers and practitioners alike learn more about this behavioural intention.

Although hampered by a lack of consensus about how to define "gangs" and "gang membership" $[9,10]$, recent research estimates that in the United States there are an estimated 25,000 gangs with nearly 750,000 members; 30 $40 \%$ of those are adolescents [11]. Previous research examining what motivates youth to join gangs has identified a multitude of intersecting variables, including the community or neighbourhood context (e.g., availability or perceived availability of drugs, community arrest rate, and availability of firearms), family dynamics (e.g., parental proviolent attitudes, child maltreatment, low attachment, and poor monitoring), socioeconomic variables (e.g., low education, poverty, and ethnic minority status), peer influences (e.g., association with peers who engage in delinquency or other problem behaviour), school factors (e.g., low academic achievement and aspirations, low commitment), and individual characteristics (e.g., violence involvement, antisocial 
beliefs, substance use, and conduct disorder) (see [12, 13]). Researchers, however, have advised that the factors associated with initial gang joining may not prove useful in predicting sustained gang involvement and continued gang involvement after reentry to the community following incarnation [14]. Consequently, research examining the factors associated with the intention to rejoin a gang after incarceration is an important direction for research so that policy can be directed at youth most likely to remain in a gang for extended periods of time, in an effort to prevent the detrimental physical, behavioural, and psychological outcomes that prolonged gang involvement has on both individuals (e.g., involvement in delinquent activity, high risk sexual activity) and society (i.e., serious and violent offences, homicides, sale and distribution of drugs, and perceptions of disorder and fear).

A small number of studies have linked having run away from home to youth gang involvement. For instance, in a sample of gang involved youth, three quarters of girls and one-third of boys reported having run away from home at least once $[15,16]$, while other research has found that many gang-affiliated youth have run away from home and joined gangs to obtain protection from dysfunctional and/or abusive family environments [17]. Research to date has not examined the relationship between having run away from home and duration of gang involvement/desistance. However, assuming that youth join gangs to escape from dysfunctional family life, it seems likely that such youth are more likely to intend to rejoin a gang after incarceration.

Ethnic minority youth are disproportionately represented in gangs, particularly Hispanic/Latino and African American youth $[13,18]$. Indeed, recent figures provided by law enforcement agencies indicate that approximately $46 \%$ of gang members are Hispanic/Latino, 35\% African-American/black, $11 \%$ white, and $7 \%$ other race/ethnicity (The National Youth Gang Survey, 2011; [11]). Moreover, Pyrooz et al. [19] found that ethnic minorities' gang involvement persists longer. A higher rate of gang affiliation among minority youth has been suggested to be in part a by-product of population migration [20, 21]. Vigil [22], for instance, suggested that immigrant youth may experience difficulties in dealing with life in a new culture, as well as language, cultural, and economic barriers, and as a result, they may perceive that they have "few options or resources to better their lives" and "seek a place where they are not marginalized" (p. 7).

1.1. Characteristics of Family. Although the family characteristics (structural variables and social process variables) of gang involved youth have not been well documented [23], solace from a violent family life, including frequent conflict and abuse among parents, has been found to be a major motivation for gang joining [24]. Furthermore, Patterson et al. [25] suggested that when family members use violence to control the behaviour of others within the family unit, children learn to control others in a similar manner and carry this forward into their interactions with others, which leads to rejection by more conventional peers and the weakening of prosocial bonds (see also [26]). As a result of this rejection, individuals might have to cope with adverse circumstances on their own, thus making them more vulnerable to both short- and long-term pressures from antisocial influences (e.g., delinquent peers, which may include youth gang members) and the internalisation of antisocial values (e.g., delinquent beliefs).

1.2. Peer Influences. Research indicates that peer delinquency (which may result in incarceration) is one of the strongest predictors of individual delinquency [27], and that gang involvement is related to affiliation with delinquent peers (e.g., [28]). However, gang membership has also been observed to be a significant predictor of individual delinquency while controlling for associations with delinquent peers [29], suggesting that gangs might be distinct from other deviant peer groups, and indicating the need to examine the impact of delinquent peer associations (as indexed by number of incarcerated friends, in this case), on the intention to rejoin a gang after incarceration.

1.3. Gang Membership Characteristics. Extensive research suggests that even in the presence of money sharing, gang membership is unlikely to offer any substantial monetary rewards. Papachristos [30], for instance, found that gang members typically make around $\$ 50$ per day by selling drugs. Given the hazards associated with drug dealing (i.e., the possibility of being arrested, robbed, or assaulted), Venkatesh [31] suggested that lucrative financial rewards are often not realised by gang-involved youth, and, consequently, prolonged gang affiliation is unlikely if money was a driving force behind the decision to join a gang. Thus, given the low probability of gang members making substantial amounts of money, it is unlikely that money sharing will significantly influence the intention to rejoin a gang after incarceration, regardless of the gang's capacity to fulfil the social needs of youths.

It is well documented that gang members face the risk of violence from within their own gang for breaking rules. Decker and Van Winkle [32], for instance, reported that rule violators were expected to walk through a line of other gang members who took turns beating the transgressor for rule transgression. Although the impact of rule-breaking punishment has on the intention to rejoin a gang following incarceration in unclear, research by Putnam [33] suggested that gang members who violate rules may be less able to return to familiar communities to take advantage of family ties and the social capital accumulated. Thus, this potential consequence may increases the relative cost of leaving a gang and result in the intention to rejoin a gang following release into the community subsequent to incarceration in prison.

An important characteristic of organized groups, such as gangs, is meetings. Meetings serve variety of functions, including enhancing group cohesion, communicating responsibilities, and disseminating information. More frequent gang contact has been suggested to lead to a decline in prosocial networks, resulting in reduced information flow, opportunities to fill structural holes, and the ability to accumulate prosocial capital (e.g., [19, 34]). Consequently, increased frequency of gang contact might reasonably be expected to be associated with an increased intention to rejoin a gang after incarceration. 
The intention to rejoin a gang following incarceration may also vary according to level of social embeddedness/ position within a gang. Horowitz [35], for instance, found that it was more difficult for core members (or those in a leadership position) to leave a gang than peripheral members, a finding consistent with Klein's [36] research in Los Angeles which found that core members were more criminally active and better integrated into, and perhaps dependent on, the group than peripheral members. In line with this, Pyrooz and colleagues [19] reported a robust relationship between "embeddedness" and continuity of gang membership. Specifically, individuals weakly embedded in gangs were found to desist at a faster rate than those more deeply embedded in gangs. Embeddedness was defined as an individual's "immersion within an enduring deviant network, restricting involvement in prosocial networks" (p. 241) and included items assessing frequency of gang contact, position in the gang, importance of gang membership, proportion of friends in the gang, and frequency of gang-involved assaults. Importantly, however, Pyrooz and colleagues looked at the factors associated with desistance for both males and females simultaneously.

Alternatively, rather than core members intending to rejoin a gang because of attenuated connections to more prosocial networks, core members may be more likely to feel the need to reassert their status within a gang following release from prison than more peripheral members [37]. Whatever the case may be, however, the pull back into a gang can be seen as amplified for more central members. By contrast, members at the fringe of a gang may find it easier to drift in and out of the gang because of less allegiance or weaker bonds to the group or other gang members [38]. Given this research, it is expected that youth who report that they have more central roles in their gangs (i.e., a leadership position) will be more likely to report intentions to rejoin a gang than those reporting regular membership.

Since membership is structured and gangs typically have both core and peripheral members, level of commitment and importance of gang membership may plausibly affect reengagement intentions. In general, the more favourable an individual's attitude towards a given behaviour, the stronger their intention to perform it [39]. Thus, individuals who view gang membership as more important should be more likely to report greater intentions to rejoin following incarceration. Research by Moffitt [40] has also found that the importance of gang affiliation to individuals can lead to the "knifing-off" of previously held prosocial attachments (i.e., conventional peers, school, and parents), which are robust correlates of delinquency.

The attenuation of prosocial bonds is also important because of the effect such ties have on conventional beliefs [26]. In light of this, we suggest that importance of gang membership will be inversely related to the likelihood of desistance from gangs (i.e., those individuals who view gang membership as particularly important should be the individuals least likely to report not intending to rejoin a gang following incarceration).

Over time, group processes and related functions lead gang members to shed their nongang friends and acquaintances [32]. Indeed, Thornberry et al. [14] referred to gangs as "social networks that embed their members in deviant routines and isolate them from prosocial arenas" (p.7). Consequently, as a result of a decline in alternative sources of support and resources, times spent with a gang might reasonably be expected to be associated with an increased intention to rejoin a gang following a period of incarceration and release back into the community.

Research on the friends of gang members has found that gangs do not typically encourage active members to have friends, particularly close ones, outside of the gang (e.g., [41]). As positive peer relationships (nongang friends, in this case) may be an important component of the identity transformation that may prevent juvenile offenders from wanting to return to the lifestyle, which may have included gang membership, which resulted in their incarceration [42], we expect that having fewer nongang member friends will be associated with intentions to rejoin a gang after incarceration. Conversely, and in line with Wood and Alleyne [10], desistance, or the intention to not rejoin a gang, might occur when prosocial opportunities and institutions are restored (i.e., stable nongang relationships) or remained intact during gang membership.

1.4. Moral Disengagement. When individuals encounter situations requiring immoral behaviour to obtain benefits, they experience moral conflicts [43]. This may lead them to engage in what Bandura [44] described as moral disengagement strategies, which consist of "cognitive restricting of inhumane conduct into a benign or worthy behaviour" [44, p. 101]. Social cognitive theory [44], much like neutralization theory [45], describes eight strategies that individuals may employ to rationalise and justify their harmful acts against others. "Moral justification," "euphemistic labelling," and "advantageous comparison" refer to mechanisms that serve to cognitively restructure harmful acts so that they appear less damaging. "Dehumanization," "distortion of consequences," and the "attribution of blame" mechanisms serve to reduce or eliminate the distress one perceives to be causing a victim. There is some data to suggest that gang members employ these techniques to cope with the negative consequence of their actions [46, 47]. Alleyne and Wood [9], for instance, found that moral disengagement strategies were more prevalent among gang-involved adolescents than their non-gangaffiliated peers. Furthermore, results of Alleyne and Wood's study indicated that although moral disengagement as a whole did not have a significant main effect, at an individual strategy level, gang members used more euphemisms and blamed their victims more than nongang youth.

1.5. Psychopathy. Research has shown that certain psychopathic traits (e.g., low empathy and poor impulse control) may be important in determining who will join a gang (e.g., $[48,49])$. Indeed, youth with psychopathic traits have been found to be five times more likely to join a gang than youth without such traits [50]. Youth with greater levels of psychopathy have been noted to be less sensitive to informal social controls (e.g., parental supervision), which have been observed to contribute (albeit modestly) to gang membership 
[51]. Furthermore, Valdez et al. [49] reported that gang members have greater Psychopathy Checklist-Screening Version (PCL-SV; [52]) total scores, as well as higher scores on the Interpersonal-Affective and Antisocial-lifestyle subscales of the measure. Similarly, another study comparing the criminal attitudes and psychopathic traits of gang- and non-gang-affiliated offenders $(N=168)$ recruited from youth correctional institutions in Singapore found that gangaffiliated youth scored significantly higher on the Impulsiveirresponsible subscale of the Youth Psychopathic Trait Inventory (YPI; [53]) than their non-gang-affiliated counterparts in univariate analysis. However, when criminal attitudes (as indexed by the Measure of Criminal Attitudes and Associates; [54]) and attitudes toward gangs were controlled for, this relationship became nonsignificant [48]. Thus, although research has shown that certain psychopathic traits may be important in determining who will join a gang, it is unclear whether such traits may influence gang reengagement intentions.

1.6. The Present Research. Given the risks associated with lengthier gang membership, the current study adds to the literature by focusing on isolating the specific factors associated with juveniles' intentions to rejoin a gang-an important predictor of continued gang involvement [19], to inform intervention efforts in detention facilities. The present study uses cross-sectional data from the Research on Pathways to Desistance (RPD) project-a large-scale study of serious adolescent offenders-to investigate the relationship between gang characteristics (money sharing, punishment for rule breaking, frequency of contact, position in the gang, importance of gang membership, number of nongang friends, and time with gang), number of incarcerated friends, and family characteristics, having run away from home and parental physical fights, controlling for ethnicity, and gang reengagement intentions. The focus of the current research is not on the effects of incarceration, because participants were interviewed within 75 days after their adjudication (for those in the juvenile system) or 90 days after their decertification hearing, but instead on previously mentioned predictors of gang reengagement after incarceration.

\section{Method}

2.1. Sample. As described in more detail elsewhere (e.g., [55]), participants were serious adolescent offenders from Philadelphia, Pennsylvania, and Phoenix who were interviewed as part of the Pathways to Desistance Study. Participants were included in the study if they (a) had been adjudicated guilty of a serious felony (excluding less serious property crimes), misdemeanour weapons, or misdemeanour sexual assault offense in juvenile or adult courts in Philadelphia or Phoenix and (b) were between the ages of 14 and 17 at the time of their offence. A total of 3,807 youths met the inclusion criteria, 1,799 of whom were excluded because of operational or design constraints. Of the youths that were located and contactable, $80 \%$ agreed to take part in the study $(N=$ 1,355). Participants were administered a baseline interview over 2 days in two, $2 \mathrm{~h}$ sessions within 75 days after their adjudication (for those in the juvenile system) or 90 days after their decertification hearing in Philadelphia or an adult arraignment in Phoenix (if in the adult system). Interviewers and participants sat side by side facing a computer, and questions were read aloud to avoid any potential difficulties arising from reading difficulties. Participants could answer the questions aloud or, to maximize their privacy, enter their responses on a keypad (although in some facilities, this option was not available). Of 1,335 participants included in the study, we selected only those reporting having been part of a gang before incarceration. Furthermore, due to very small number, we excluded females $(n=28)$ from the analysis, which resulted in a sample of 206 male gang members.

\subsection{Measures}

2.2.1. Gang Membership Characteristics. A series of questions adapted from studies by Thornberry et al. [56] and Elliot [57] were used to assess characteristics of gang membership. Consistent with a long line of gang research, self-nomination was used to operationalize gang membership (i.e., participants were asked if they were "ever in a gang"). If gang involvement was endorsed, additional items were asked to explore individual's subjective experience of the gang and gang cohesiveness. For this study, we focused on the following items: "does your gang/posse share money?" (yes/no); "does your gang/posse have punishments for breaking the rules?" (yes/no); "in the past six months, before you came into the system on this charge, how often did you have contact with the gang/posse?" (less than monthly, once per month, less than weekly but more than monthly, once per week, twice per week, 3-6 times per week, and daily); "what is/was your position in the gang/posse?" (leader/member); "how important is the gang/posse to you?" ( $1=$ not at all to $5=$ extremely); "how many of your friends are not members of the gang/posse?" (none, a few are not members, half are not members, most are not members, and all). The item "do you expect to be a member when back on the street?" (yes/no) was used to assess the intention to rejoin a gang following incarceration.

2.2.2. Number of Incarcerated Friends. Participants were asked to report the number of friends that they had who have been in prison (count variable).

2.2.3. Run Away from Home. Participants were asked to respond to a single item which asked, "Have you ever run away from where you were living?" (yes/no).

2.2.4. Characteristics of Family. Family characteristics were assessed using two binary coded (yes/no) items which asked "has anyone in your family been in jail or prison?" and "did your parents have physical fights?"

2.2.5. Psychopathy. The Psychopathy Checklist-Youth Version (PCL-YV; [58]) was used to assess youths' psychopathic traits. This 20-item rating scale is based on two sources: (1) an interview with the youth and (2) charts and collateral information. The original semistructured interview guide was adapted for use in this study and reviewed with the 
TABLE 1: Descriptive statistics for age, number of incarcerated friends, gang characteristics, moral disengagement, and the two psychopathy factors.

\begin{tabular}{lcccc}
\hline Variable & Minimum & Maximum & M & SD \\
\hline Age & 14 & 18 & 16.03 & 1.10 \\
$\begin{array}{l}\text { Number of } \\
\text { incarcerated friends }\end{array}$ & 0 & 4 & 1.59 & 1.30 \\
$\begin{array}{l}\text { Frequency of contact } \\
\text { with gang members }\end{array}$ & 1 & 7 & 2.31 & 2.14 \\
$\begin{array}{l}\text { Importance of gang } \\
\text { membership }\end{array}$ & 0 & 4 & 1.83 & 1.49 \\
$\begin{array}{l}\text { Number of friends } \\
\text { (nongang members) }\end{array}$ & 1 & 5 & 2.37 & 1.05 \\
$\begin{array}{l}\text { Age of initiation to } \\
\text { gang }\end{array}$ & 9 & 17 & 12.62 & 2.02 \\
$\begin{array}{l}\text { Moral disengagement } \\
\text { PCL YV-Factor 1 }\end{array}$ & 0 & 28 & 9.51 & 5.95 \\
PCL YV-Factor 2 & 1 & 19 & 6.30 & 3.61 \\
\hline
\end{tabular}

Frequency of contact with gang members was categorised as $1=$ less than monthly, 2 = once per month, 3 = less than weekly but more than monthly, 4 $=$ once per week, $5=$ twice per week, $6=3-6$ times per week, and $7=$ daily. Importance of gang membership was rated as $1=$ not at all to $5=$ extremely.

interview's developer. Following the interview and a review of records/collateral information, the interviewer used a 3-point ordinal scale to indicate how well each of the 20 items applied to the youth $(0=$ does not apply, $1=$ applies to a certain extent, and 2 =applies). A two-factor solution (Factor 1: Interpersonal-Affective and Factor 2: Antisocial-lifestyle) to the PCL-SV was adopted in the present research, although 3- and 4-factor solutions have been found to provide better model fit (see [59]) due to these researchers being unable to access all PCL-SV item scores (see http://www.pathwaysstudy.pitt.edu/codebook/pcl-sb.html). Internal consistency of Factor $1(\alpha=.76)$ and Factor $2(\alpha=$ .78) was good.

2.2.6. Moral Disengagement. The Mechanisms of Moral Disengagement [60] was used for this study to measure adolescent's attitudes concerning the treatment of others. The self-report measure contains 32 items to which participants respond on a 3 -point Likert scale ( $1=$ Disagree to $3=$ Agree $)$, with higher scores indicating a greater moral detachment. Mean item total scores were used as an overall scale measure of moral disengagement $(\alpha=.88)$.

2.2.7. Demographics. We control race/ethnicity (dummy coded as Hispanic or Non-Hispanic) and gender. To control for gender, we excluded females from the analysis, since they exhibited much lower levels of gang activity.

\section{Results}

3.1. Descriptive Statistics. Descriptive statistics for all continuous variables are presented in Table 1, while descriptive statistics for all categorical variables are presented in Table 2. The mean age of participants at the time of adjudication was 16.03 years $(\mathrm{SD}=1.10)$, while the average age of gang initiation
TABLE 2: Frequencies of endorsement for all categorical variables.

\begin{tabular}{lcc}
\hline Variable & Frequency & $\%$ \\
\hline Ethnicity & & \\
Non-Hispanic (0) & 78 & 37.9 \\
Hispanic (1) & 128 & 62.1
\end{tabular}

Have you ever run away from where you were living?

$\begin{array}{lcc}\text { Yes (1) } & 94 & 45.6 \\ \text { No (0) } & 112 & 54.4 \\ \text { id your parents have physical fights? } & & \\ \text { Yes (1) } & 58 & 28.2 \\ \text { No (0) } & 148 & 71.8 \\ \text { oes gang share money? } & & \\ \text { Yes (1) } & 143 & 69.4 \\ \text { No (0) } & 62 & 30.1 \\ \text { Missing value } & 1 & .5\end{array}$

Does gang have punishment if rules are broken?

\begin{tabular}{lcc} 
Yes (1) & 108 & 52.4 \\
No (0) & 97 & 47.1 \\
Missing value & 1 & .5 \\
Oosition in gang & & \\
Regular member (0) & 152 & 73.8 \\
Leader or one of the top man (1) & 54 & 26.2 \\
tention to rejoin the gang after & & \\
Yearceration & & \\
No $(0)$ & 110 & 53.4 \\
& 96 & 46.6 \\
\hline
\end{tabular}

was 12.62 years $(\mathrm{SD}=2.02)$. The sample was primarily Hispanic (62.1\%), and of the 152 regular members and 54 leaders/top men in a gang, more than half (53.4\%) reported the intention to rejoin a gang following incarceration.

3.2. Binary Logistic Regression. Direct binary logistic regression was used to assess the impact of ethnicity, having run away from home, parental fighting, number of incarcerated friends, gang characteristics (money sharing, punishment for rule violation, frequency of contact, position, importance of gang membership, time spent with gang members, and number of nongang friends), moral disengagement, and the two psychopathy factors on the likelihood of reporting intentions to rejoin a gang following incarceration. Preliminary analyses were conducted to ensure no violation of the assumption of multicollinearity (see Table 3). Little's MCAR test (1998) indicated that data was not missing completely at random $\left(\chi^{2}=214.99, \mathrm{df}=78 ; P<.001\right)$. Consequently, missing values were problematic and regression analysis was conducted without imputation being made (missing cases were removed from final analysis).

A test of the full model containing all predictor variables against a constant-only model was statistically significant $\left(\chi^{2}=82.27, P<.001\right)$, indicating that the model was able 
TABLE 3: Correlations between all independent variables.

\begin{tabular}{|c|c|c|c|c|c|c|c|c|c|c|c|c|c|}
\hline Variable & 1 & 2 & 3 & 4 & 5 & 6 & 7 & 8 & 9 & 10 & 11 & 12 & 13 \\
\hline (1) Ethnicity & - & & & & & & & & & & & & \\
\hline $\begin{array}{l}\text { (2) Have you ever run away from where you } \\
\text { were living? }\end{array}$ & -.06 & - & & & & & & & & & & & \\
\hline (3) Did your parents have physical fights? & -.03 & $.24^{* *}$ & - & & & & & & & & & & \\
\hline (4) Number of incarcerated friends & -.03 & $.14^{* *}$ & $.11^{* *}$ & - & & & & & & & & & \\
\hline (5) Does gang share money? & -.10 & .02 & .05 & $.24^{* *}$ & - & & & & & & & & \\
\hline $\begin{array}{l}\text { (6) Does gang have punishment if rules are } \\
\text { broken? }\end{array}$ & -.04 & .06 & .07 & .07 & .12 & - & & & & & & & \\
\hline (7) Frequency of contact with gang members & -.06 & $.26^{* *}$ & $.12^{* *}$ & .13 & $.15^{*}$ & -.09 & - & & & & & & \\
\hline (8) Position in gang & $.09^{* *}$ & .05 & -.02 & $.07^{*}$ & $.15^{*}$ & $.17^{*}$ & .01 & - & & & & & \\
\hline (9) Importance of gang membership & -.04 & $.10^{* *}$ & .06 & $.26^{* *}$ & $.21^{* *}$ & .13 & $.21^{* *}$ & -.01 & - & & & & \\
\hline (10) Number of friends (nongang members) & -.04 & -.04 & .06 & .01 & -.01 & .10 & $-.35^{* *}$ & .09 & $-.14^{*}$ & - & & & \\
\hline (11) Time with the gang & .04 & .06 & $.24^{* *}$ & $.15^{*}$ & .08 & .10 & .05 & $.13^{*}$ & $.15^{*}$ & .01 & - & & \\
\hline (12) Moral disengagement & .05 & $.11^{* *}$ & $.10^{* *}$ & $.11^{* *}$ & .05 & .04 & .12 & $.10^{* *}$ & .12 & -.01 & .01 & - & \\
\hline (13) PCL YV-Factor 1 & .04 & .07 & .04 & $.13^{* *}$ & $.17^{*}$ & .06 & .04 & $.09^{* *}$ & $.16^{*}$ & .13 & $.14^{*}$ & $.29^{* *}$ & - \\
\hline (14) PCL YV-Factor 2 & .04 & $.12^{* *}$ & $.13^{* *}$ & $.20^{* *}$ & .09 & .13 & .09 & $.10^{* *}$ & $.22^{* *}$ & .01 & $.21^{* *}$ & $.26^{* *}$ & $.61^{* *}$ \\
\hline
\end{tabular}

Note. ${ }^{*} P<.05 ;{ }^{* *} P<.01$.

TABLE 4: Logistic regression model of the predictors of gang reengagement intentions.

\begin{tabular}{lccc}
\hline Variable & $B$ & SE & OR (95\% CI) \\
\hline Ethnicity & -.43 & .40 & $.65(.30 / 1.41)$ \\
Have you ever run away from where you were living? & .19 & .40 & $.20(.55 / 2.66)$ \\
Did your parents have physical fights? & -.55 & .44 & $.58(.25 / 1.35)$ \\
Number of incarcerated friends & .22 & .16 & $1.25(.92 / 1.35)$ \\
Does gang share money? & -.52 & .44 & $.60(.25 / 1.42)$ \\
Does gang have punishment if rules are broken? & -.99 & .41 & $.37^{*}(.17 / .83)$ \\
Frequency of contact with gang members & -.02 & .09 & $.98(.82 / 1.17)$ \\
Position in gang & .48 & .44 & $1.62(.68 / 3.85)$ \\
Importance of gang membership & .94 & .16 & $.2 .55^{* * *}(1.87 / 3.48)$ \\
Number of friends (nongang members) & -.40 & .20 & $.67^{*}(.45 / .99)$ \\
Time with the gang & .14 & .16 & $1.16(.85 / 1.57)$ \\
Moral disengagement & .11 & .04 & .07 \\
PCL YV-Factor 1 & -.01 & .07 & $.99(.06 / 1.15)$ \\
PCL YV- Factor 2 & -.08 & $.94 / 1.20)$ \\
\hline
\end{tabular}

Note. Dependent variable: intention to rejoin gang after incarceration. $\mathrm{OR}=$ odds ratio. $\mathrm{SE}=$ standard error. $95 \% \mathrm{CI}=$ confidence interval. ${ }^{*} P<.05 ;{ }^{* *} P<$ $.01{ }^{* * *} P<.001$.

to distinguish between individuals reported intentions to rejoin a gang after being incarcerated and those not reporting such intentions. The Cox and Snell $R^{2}$ value was .35 and Nagelkerke $R^{2}$ was .47 . The model displayed satisfactory positive predictive value correctly classifying $80.1 \%$ of cases.

As shown in Table 4, only three of the variables made a unique statistically significant contribution to the model (punishment if gang rules are broken, importance of gang membership, and moral disengagement). The strongest predictor to belonging to the gang reengagement intention group was importance of gang membership (OR $=2.55, P<$ $.001)$. This result indicates that for every unit increase in importance of gang membership, an individual was 2.55 times more likely to express the intention to rejoin a gang group, while controlling for all other factors in the model. Moral disengagement was also positively related to reengagement intentions ( $\mathrm{OR}=1.11, P<.05)$, while number of nongang friends was negatively related to reengagement intentions $(\mathrm{OR}=.67, P<.05)$, while controlling for all other factors in the model. This suggests that for every unit increase in moral disengagement, an individual was 1.11 times more likely to endorse the intention to rejoin a gang group, while for every unit increase in nongang friends, individuals were less likely to rejoin the gang.

\section{Discussion}

Although research has established that intentions are the most immediate and important determinants of behaviour action (e.g., [4, 5]), and work by Pyrooz et al. [19] established 
the relevance of behavioural intentions for continued gang involvement, the correlates of this important indicator have not been previously examined. The aim of this research, therefore, was to specify and test a model to explain why young offenders intend to reengage with gangs to which they previously belonged. The model explained between 35\% and $47 \%$ of variance in gang reengagement intentions and successfully distinguished rejoiners from those not signalling an intention to rejoin.

Although the model overall explained a sizeable about of variance of gang reengagement intentions, only punishment if gang rules are broken, importance of gang membership, and moral disengagement made unique statistically significant contributions to the model. The significant influence of fear of retribution for gang rule infringements on intentions to remain a gang member supports the hypothesis that it may be perceived by gang members to be safer and less costly to rejoin rather than to leave [33]. It is not clear, however, if respondents expressing this view had knowingly broken the rules or were concerned that if they refrain from rejoining the gang on release, this would feed the suspicion that information about the gang had been disclosed to the authorities whilst in custody putting them at even greater risk.

Neither psychopathy factor significantly influenced the intention to rejoin the gang postincarceration. Consequently, despite research suggesting that youths with psychopathic traits are five times more likely to join a gang than those without [50], results of the present research indicate that psychopathy is neither a risk factor for reengagement nor an influence on the intention to sever links. This suggests that prioritising working with young offenders displaying psychopathic traits would be an ineffective means of attempting to prevent reengagement with gangs following incarceration. This is a useful finding, particularly if it is replicated in other studies, in that it potentially spares criminal justice and social work practitioners from concentrating their efforts and scarce resources on psychopathic young offenders who are at no greater or lesser risk of resuming gang membership, following release from prison, than any other gang member.

By contrast, the number of friends of young offenders had, who were not involved with gangs, was, as hypothesised, a significant factor in the extent to which offenders were likely to reengage with gangs following incarceration. The lack of "normal" friends meant a greater likelihood of rejoining a gang. This suggests that the exposure of young offenders to lifestyles and behaviours other than those associated with the close-knit culture and daily experience of gang membership reduced their need to rejoin gangs following release from prison. It is interesting to speculate on how this effect arises. One explanation might be that commitment to a gang is somewhat weaker among young offenders with non-gang-involved friends and that this is later reflected in a diminished desire to rejoin postincarceration. Youth diversion programmes that steer youth away from gangs and boost their exposure to a wider range of lifestyles and role models may have some success, even among gang members, in severing their links with gangs after release [9]. This begs a question about the presence of nongang members and prosocial role models among peer groups within the communities in which the young offenders live. It may be more difficult to avoid recruitment by gangs or escape their influence in highly criminogenic ethnically segregated poorer neighbourhoods [61]. Within the prison environment, the implication of this finding suggests that there might be some merit in ensuring that gang-involved young offenders are not placed in the same cells.

The positive relationship between moral disengagement and reintegration suggests that this cognitive mechanism is a particularly effective "moral shield" for gang-involved young offenders, whether on the streets, during imprisonment, or following release. This relationship is also entirely consistent with the negative association between the number of non-gang-involved friends and the decision to rejoin. The moral disengagement of young offenders from society, at large, is likely to be preserved within a close-knit gang community, isolated from prosocial influences and governed by strict rules, but challenged and potentially weakened, when exposed to the cultural norms, values, and behaviour of nongang members.

Even though risk factors for rejoining a gang may be identifiable, knowing how and when to intervene to neutralise or reverse them is a considerable challenge. The timeline for intervention is potentially lengthy, involving action preincarceration, during imprisonment and following release. Ideally, the most desirable outcome would be to prevent gang formation and recruitment at the outset but there may be options to intervene during a period of incarceration to reduce the likelihood of reintegration after release. Identifying which factors influence young offenders to rejoin gangs, as this paper has demonstrated, does not automatically lead to the implementation of appropriate interventions and countermeasures. The success of interventions in reducing recidivism generally is mixed and the evidence base of "what works" is sparse, although there is evidence that incarcerating gang members, curriculum-based prevention programmes, and using adult prison visits to scare minor juvenile offenders do not reduce the chances of reoffending and in some cases can be harmful $[62,63]$. However, the findings from this paper do provide some clues about the general direction preventive approaches might take.

The most significant finding is the discovery that psychopathy among young offenders has no influence on their intention to reengage with gangs, once they have left prison. This is important because it suggests that psychopathy would not be an obstacle to steering young offenders away from reengagement with gangs. Unlike psychopathy, other drivers of reengagement may be more amenable to attenuation through targeted projects and interventions.

The intention to reengage with gangs, and indeed their perceived importance, indicates that they fulfil a need in young people for belonging and identity. But their attraction also signals that there is a lack of alternatives to gang membership and opportunities for young people, which become particularly marked at the point of release. It is at this stage, that they need help with resettlement, health, and housing needs, support with skills and training, access to employment opportunities, and other forms of assistance that provide attractive alternatives to gang membership. A 
recent systematic review of "focused deterrent strategies" targeting gangs and criminally active groups suggests that offering gang members job training, employment, substance abuse treatment, housing assistance, and a variety of other services and opportunities produces large statistically significant reductions in violent crime [64]. Other approaches, using a varied menu of law enforcement sanctions to curtail violent behaviour (so-called "pulling levers") and incentives focusing social services and community resources to targeted offenders have shown promising results [65].

The findings from this study also indicate a need to challenge young offenders' perceptions about the importance of gang membership, particularly its disadvantages and the costs of membership for familial relationships and quality of life. The impact of having non-gang-involved friends on the intention not to rejoin gangs also suggests that there may be merit in demonstrating to young offenders that there are alternative, more rewarding lifestyles to gang culture and that it is possible to exit from gangs without coming to harm. The findings also suggest that promoting young offenders' moral reengagement would have a significant effect on the likelihood that young offenders will not rejoin gangs on release. The objectives are clear but the means by which they might be realised is another matter entirely.

Notwithstanding these suggestions, it is necessary to highlight some caveats surrounding the broader applicability of this research to policy. Firstly, additional studies are required to corroborate the findings (the sample was drawn from a limited young offender population that was primarily Hispanic). Secondly, it would be advantageous to undertake an analysis with a larger array of measures to create a more extensive evidence base on risk and protective factors influencing gang reintegration. Thirdly, as gang members were incarcerated for no more than 90 days, further studies examining gang members' responses to the intention question are advisable because participants' responses may change significantly after "fully" experiencing incarceration. Finally, as the question on the intention to resume gang membership was dichotomous, future research might usefully explore conditions attached to rejoining in order to test the determination, by the offender, to become a gang member once again.

\section{Conflict of Interests}

The authors declare that there is no conflict of interests regarding the publication of this paper.

\section{References}

[1] D. K. Marvin and T. P. Thornberry, "Longitudinal perspectives on adolescent street gangs," in The Long View of Crime: A Synthesism of Longitudinal Research, A. K. Liberman, Ed., pp. 128-160, National Institute of Justice, Washington, DC, USA, 2008.

[2] H. C. Triandis, "Values attitudes and interpersonal behaviour," in Nebraska Symposium on Motivation: Beliefs Attitudes and Values, H. E. Howe and M. M. Page, Eds., vol. 27, pp. 195-259, University of Nebraska Press, Lincoln, Neb, USA, 1980.
[3] I. Ajzen, "The theory of planned behavior," Organizational Behavior and Human Decision Processes, vol. 50, no. 2, pp. 179211, 1991.

[4] I. Ajzen and M. Fishbein, Understanding Attitudes and Predicting Social Behavior, Prentice-Hall, Englewood Cliffs, NJ, USA, 1980.

[5] M. Fishbein and I. Ajzen, Belief Attitude Intention and Behavior: An Introduction to Theory and Research, Addison-Wesley, Reading, Mass, USA, 1975.

[6] R. P. Bagozzi, "The self-regulation of attitudes, intentions, and behavior," Social Psychology Quarterly, vol. 55, no. 2, pp. 178204, 1992.

[7] M. D. Krohn, J. T. Ward, T. P. Thornberry, A. J. Lizotte, and R. Chu, "The cascading effects of adolescent gang involvement across the life course," Criminology, vol. 49, no. 4, pp. 991-1028, 2011.

[8] C. Melde and F.-A. Esbensen, "Gangs and violence: disentangling the impact of gang membership on the level and nature of offending," Journal of Quantitative Criminology, vol. 29, no. 2, pp. 143-166, 2013.

[9] E. Alleyne and J. L. Wood, "Gang involvement: psychological and behavioral characteristics of gang members, peripheral youth, and nongang youth," Aggressive Behavior, vol. 36, no. 6, pp. 423-436, 2010.

[10] J. Wood and E. Alleyne, "Street gang theory and research: where are we now and where do we go from here?" Aggression and Violent Behavior, vol. 15, no. 2, pp. 100-111, 2010.

[11] A. Egley Jr. and J. C. Howell, Highlights of the 2011 National Youth Gang Survey, Office of Juvenile Justice and Delinquency Prevention, Washington, DC, USA, 2013.

[12] J. C. Howell and A. Egley, "Moving risk factors into developmental theories of gang membership," Youth Violence and Juvenile Justice, vol. 3, no. 4, pp. 334-354, 2005.

[13] M. W. Klein and C. L. Maxson, Gang Structures, Crime Patterns, and Police Responses, Social Science Research Institute, University of Southern California, Los Angeles, Calif, USA, 2006.

[14] T. Thornberry, M. Krohn, A. Lizotte, C. Smith, and K. Tobin, Gangs and Delinquency in Developmental Perspective, Cambridge University Press, New York, NY, USA, 2003.

[15] J. W. Moore and J. M. Hagedorn, "What happens to girls in the gang," Gangs in America, vol. 2, pp. 205-218, 1996.

[16] A. Valdez, Mexican American Girls and Gang Violence: Beyond Risk, Palgrave Macmillan, New York, NY, USA, 2007.

[17] M. Chesney-Lind, R. G. Shelden, and K. A. Joe, "Girls delinquency and gang membership," Gangs in America, vol. 2, no. 1, pp. 185-204, 1996.

[18] F. A. Esbensen and D. C. Carson, "Who are the gangsters? An examination of the age, race/ethnicity, sex, and immigration status of self-reported gang members in a seven-city study of American youth," Journal of Contemporary Criminal Justice, vol. 28, no. 4, pp. 465-481, 2012.

[19] D. C. Pyrooz, G. Sweeten, and A. R. Piquero, "Continuity and change in gang membership and gang embeddedness," Journal of Research in Crime and Delinquency, vol. 50, no. 2, pp. 239-271, 2013.

[20] J. D. Vigil, "Mexican migrants in gangs: a second generation history," in Street Gangs Migration and Ethnicity, pp. 49-62, 2008.

[21] C. Adamson, "Defensive localism in white and black: a comparative history of European-American and African-American youth gangs," Ethnic and Racial Studies, vol. 23, no. 2, pp. 272298, 2000. 
[22] D. Vigil, "Community dynamics and the rise of street gangs," in Latinos: Remaking America, pp. 97-109, 2002.

[23] M. W. Klein and C. L. Maxson, "Street gang violence," in Violent Crime. Violent Criminals, pp. 198-234, 1989.

[24] J. Miller, One of the Guys: Girls Gangs and Gender, Oxford University Press, New York, NY, USA, 2001.

[25] G. R. Patterson, B. D. DeBaryshe, and E. Ramsey, "A developmental perspective on antisocial behavior," American Psychologist, vol. 44, no. 2, pp. 329-335, 1989.

[26] T. Hitschi, Causes of Delinquency, University of California Press, Berkeley, Calif, USA, 1969.

[27] D. Boduszek, G. Adamson, M. Shevlin, P. Hyland, and K. Dhingra, "Psycho-sociological investigation of criminal behaviour within a prison sample using retrospective data," The Howard Journal of Criminal Justice, vol. 53, no. 1, pp. 31-48, 2014.

[28] K. G. Hill, J. C. Howell, J. D. Hawkins, and S. R. BattinPearson, "Childhood risk factors for adolescent gang membership: results from the Seattle Social Development Project," Journal of Research in Crime and Delinquency, vol. 36, no. 3, pp. 300-322, 1999.

[29] S. R. Battin, K. G. Hill, R. D. Abbott, R. F. Catalano, and J. D. Hawkins, "The contribution of gang membership to delinquency beyond delinquent friends," Criminology, vol. 36, no. 1, pp. 93-116, 1998.

[30] A. V. Papachristos, "Gang world," Foreign Policy, no. 147, pp. 4855, 2005.

[31] S. Venkatesh, "The financial activity of a modern American street gang," in Looking at Crime from the Street Level: Plenary papers of the 1999 Conference on Criminal Justice Research and Evaluation-Enhancing Policy and Practice through Research, vol. 1, pp. 2-3, 1999.

[32] S. H. Decker and B. Van Winkle, Life in the Gang: Family Friends and Violence, Cambridge University Press, New York, NY, USA, 1996.

[33] R. Putnam, Bowling Alone: The Collapse and Revival of American Community, Simon and Schuster, New York, NY, USA, 2000.

[34] R. Burt, Structural Holes: The Social Structure of Competition, Harvard University Press, Cambridge, Mass, USA, 1992.

[35] R. Horowitz, Honor and the American Dream: Culture and Social Identity in a Chicano Community, Rutgers University Press, New Brunswick, NJ, USA, 1983.

[36] M. W. Klein, Street Gangs and Street Workers, Prentice-Hall, Englewood Cliffs, NJ, USA, 1971.

[37] E. Anderson, Code of the Street: Decency Violence and the Moral Life of the Inner City, WW Norton \& Company, New York, NY, USA, 1999.

[38] J. M. Hagedorn, "Homeboys dope fiends legits and new jacks," Criminology, vol. 32, no. 2, pp. 197-219, 1994.

[39] C. J. Armitage and M. Conner, "Efficacy of the theory of planned behaviour: a meta-analytic review," British Journal of Social Psychology, vol. 40, no. 4, pp. 471-499, 2001.

[40] T. E. Moffitt, "Adolescence-limited and life-course-persistent antisocial behavior: a developmental taxonomy," Psychological Review, vol. 100, no. 4, pp. 674-701, 1993.

[41] S. Hymel, E. Wagner, and L. J. Butler, "Reputational bias: view from the peer group," in Peer Rejection in Childhood, S. R. Asher and J. D. Coie, Eds., pp. 156-188, Cambridge University Press, New York, NY, USA, 1990.

[42] H. J. Laub and J. R. Sampson, "Understanding desistance from crime," in Crime and Justice: A Review of Research, pp. 1-69, The University of Chicago Press, Chicago, Ill, USA, 2001.
[43] A. Bandura, "Selective activation and disengagement of moral control," Journal of Social Issues, vol. 46, no. 1, pp. 27-46, 1990.

[44] A. Bandura, "Selective moral disengagement in the exercise of moral agency," Journal of Moral Education, vol. 31, no. 2, pp. 101$119,2002$.

[45] G. M. Sykes and D. Matza, "Techniques of neutralization: a theory of delinquency," American Sociological Review, vol. 22, no. 6, pp. 664-670, 1957.

[46] F. A. Esbensen and F. M. Weerman, "Youth gangs and troublesome youth groups in the United States and the Netherlands: a cross-national comparison," European Journal of Criminology, vol. 2, no. 1, pp. 5-37, 2005.

[47] F.-A. Esbensen, D. Peterson, T. J. Taylor, and A. Freng, "Similarities and differences in risk factors for violent offending and gang membership," Australian \& New Zealand Journal of Criminology, vol. 42, no. 3, pp. 310-335, 2009.

[48] C. M. Chu, M. Daffern, S. D. M. Thomas, Y. Ang, and M. Long, "Criminal attitudes and psychopathic personality attributes of youth gang offenders in Singapore," Psychology, Crime and Law, vol. 20, no. 3, pp. 284-301, 2014.

[49] A. Valdez, C. D. Kaplan, and E. Codina, "Psychopathy among Mexican American gang members: a comparative study," International Journal of Offender Therapy and Comparative Criminology, vol. 44, no. 1, pp. 46-58, 2000.

[50] V. Dupéré, É. Lacourse, J. D. Willms, F. Vitaro, and R. E. Tremblay, "Affiliation to youth gangs during adolescence: The interaction between childhood psychopathic tendencies and neighborhood disadvantage," Journal of Abnormal Child Psychology, vol. 35, no. 6, pp. 1035-1045, 2007.

[51] M. le Blanc and N. Lanctot, "Social and psychological characteristics of gang members according to the gang structure and its subcultural and ethnic makeup," Journal of Gang Research, vol. 5, no. 3, pp. 15-28, 1998.

[52] S. D. Hart, D. N. Cox, and R. D. Hare, The Hare Psychopathy Checklist: Screening Version (PCL: SV), Multi-Health Systems Incorporated, 1995.

[53] H. A. Andershed, M. Kerr, H. Stattin, and S. Levander, "Psychopathic traits in non-referred youths: a new assessment tool," in Psychopaths: Current International Perspectives, E. Blauuw and L. Sheridan, Eds., pp. 131-158, Elsevier, The Hague, The Netherlands, 2002.

[54] J. F. Mills, D. G. Kroner, and T. Hemmati, "The Measures of Criminal Attitudes and Associates (MCAA) - the prediction of general and violent recidivism," Criminal Justice and Behavior, vol. 31, no. 6, pp. 717-733, 2004.

[55] C. A. Schubert, E. P. Mulvey, L. Steinberg et al., "Operational lessons from the pathways to desistance project," Youth Violence and Juvenile Justice, vol. 2, no. 3, pp. 237-255, 2004.

[56] T. P. Thornberry, J. A. Lizotte, D. M. Krohn, M. Farnworth, and J. S. Jang, "Delinquent peers beliefs and delinquent behavior: a longitudinal test of interactional theory," Criminology, vol. 32, no. 1, pp. 47-83, 1994.

[57] D. S. Elliot, National Youth Survey, Institute of Behavioral Science, University of Colorado, 1990.

[58] A. E. Forth, D. S. Kosson, and R. D. Hare, Hare Psychopathy Checklist: Youth Version (PCL: YV), MHS, 2003.

[59] K. Dhingra and D. Boduszek, "Psychopathy and criminal behaviour: a psychosocial research perspective," Journal of Criminal Psychology, vol. 3, no. 2, pp. 83-107, 2013.

[60] A. Bandura, C. Barbaranelli, G. V. Caprara, and C. Pastorelli, "Multifaceted impact of self-efficacy beliefs on academic functioning," Child Development, vol. 67, no. 3, pp. 1206-1222, 1996. 
[61] W. William, The Truly Disadvantaged: The Inner City the Underclass and Public Policy, University of Chicago Press, Chicago, Ill, USA, 1987.

[62] S. Aos, M. Miller, and E. Drake, Evidence-Based Public Policy Options to Reduce Future Prison Construction Criminal Justice Costs and Crime Rates, Washington State Institute for Public Policy, Olympia, Wash, USA, 2006.

[63] L. W. Sherman, D. Gottfredson, D. MacKenzie, J. Eck, P. Reuter, and S. Bushway, Preventing Crime: What Works, What Doesn't, What's Promising, National Institute of Justice Research Brief, 1998.

[64] A. A. Braga and D. L. Weisburd, "The effects of "pulling levers" focused deterrence strategies on crime," Campbell Systematic Reviews, vol. 8, no. 6, pp. 1-90, 2012.

[65] D. M. Kennedy, Deterrence and Crime Prevention: Reconsidering the Prospect of Sanction, vol. 2, Routledge, 2009. 

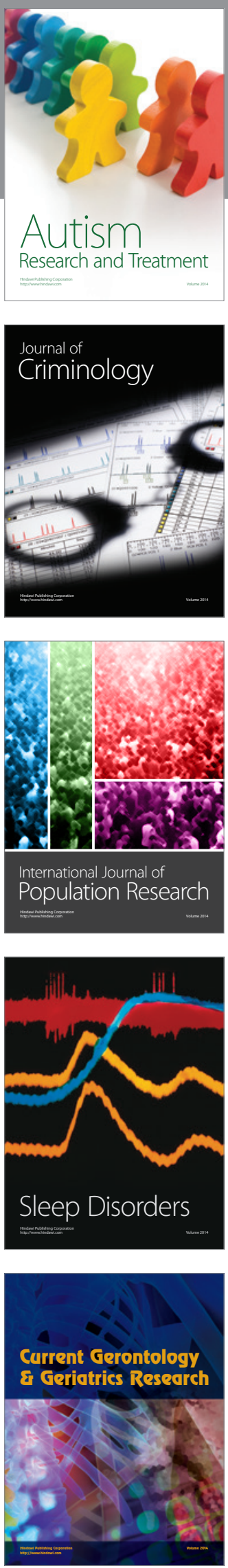
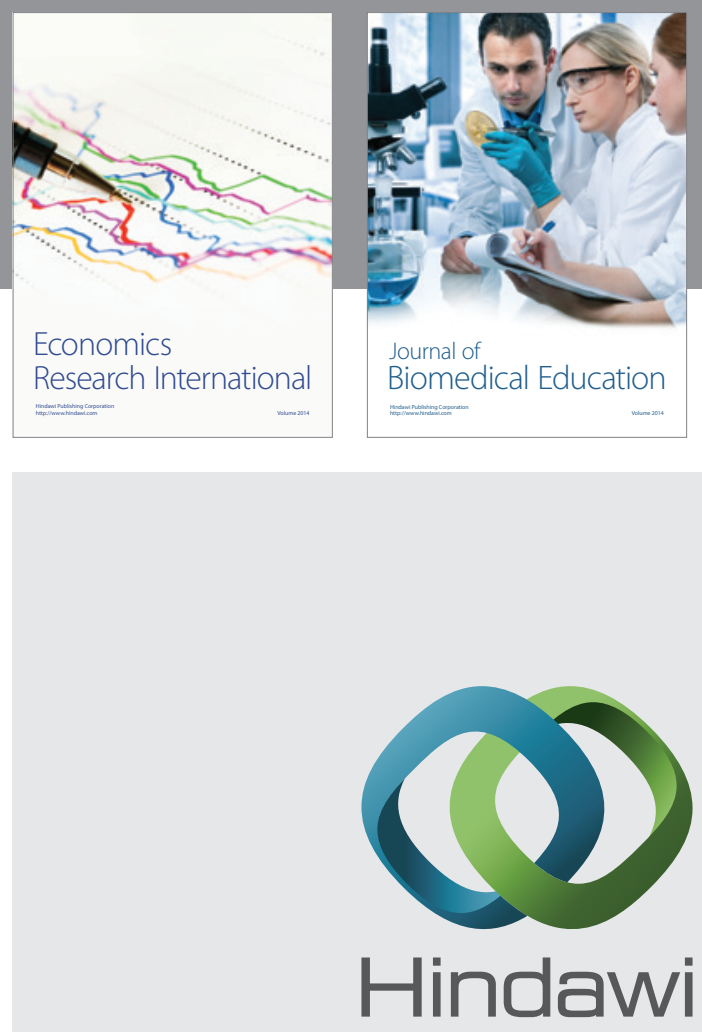

Submit your manuscripts at

http://www.hindawi.com
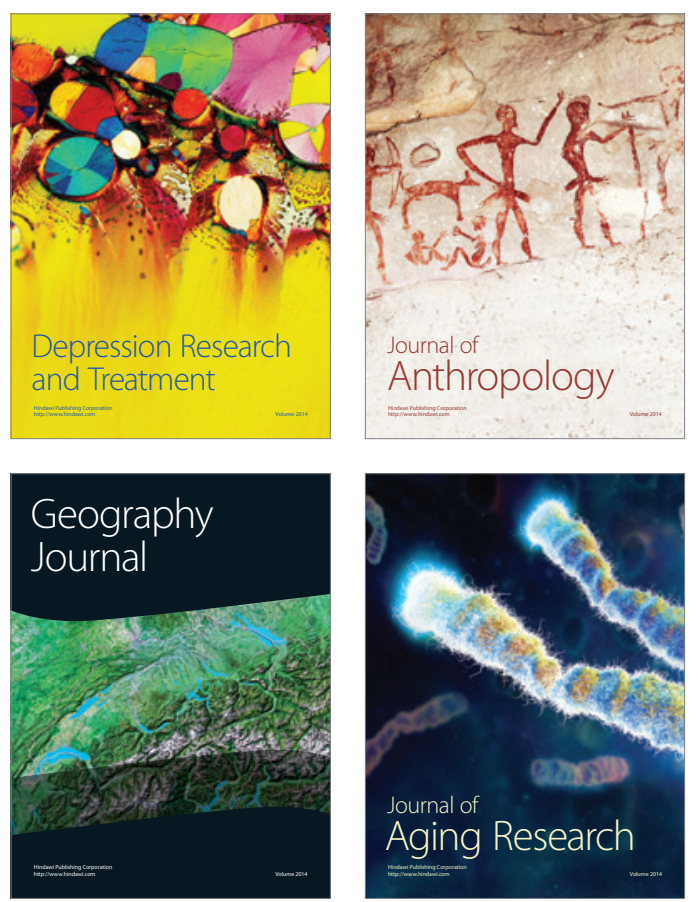
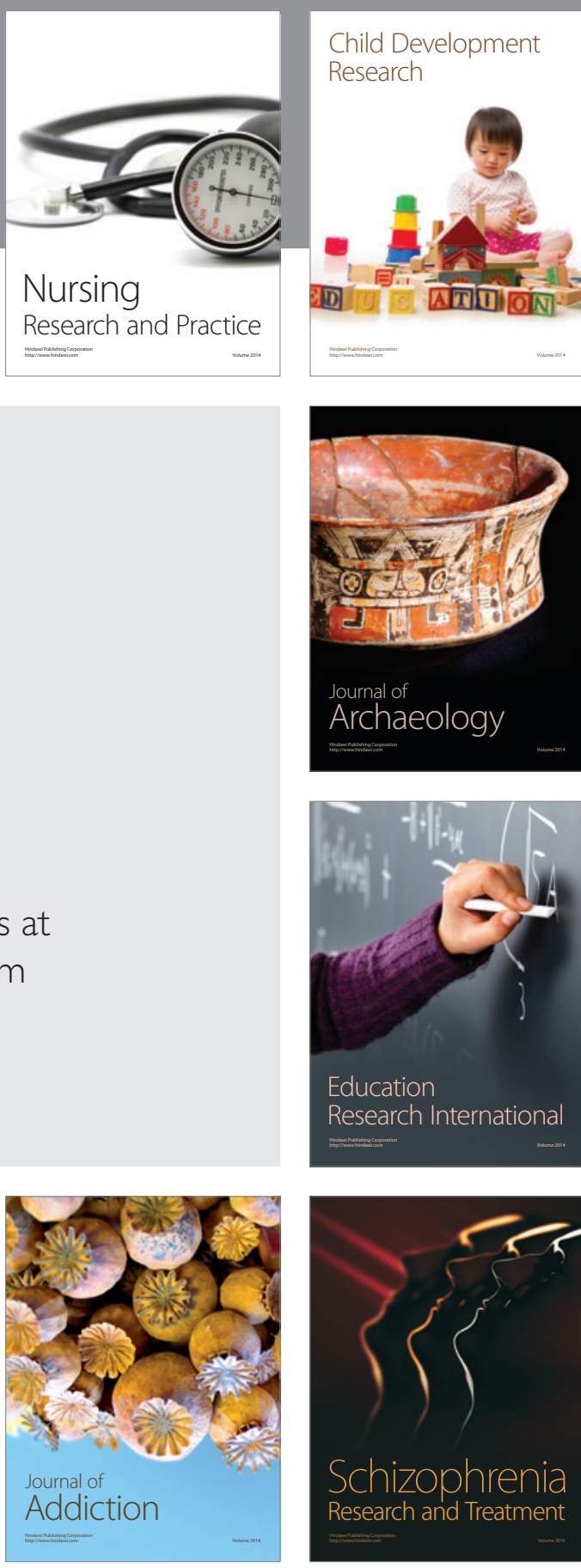

(D)
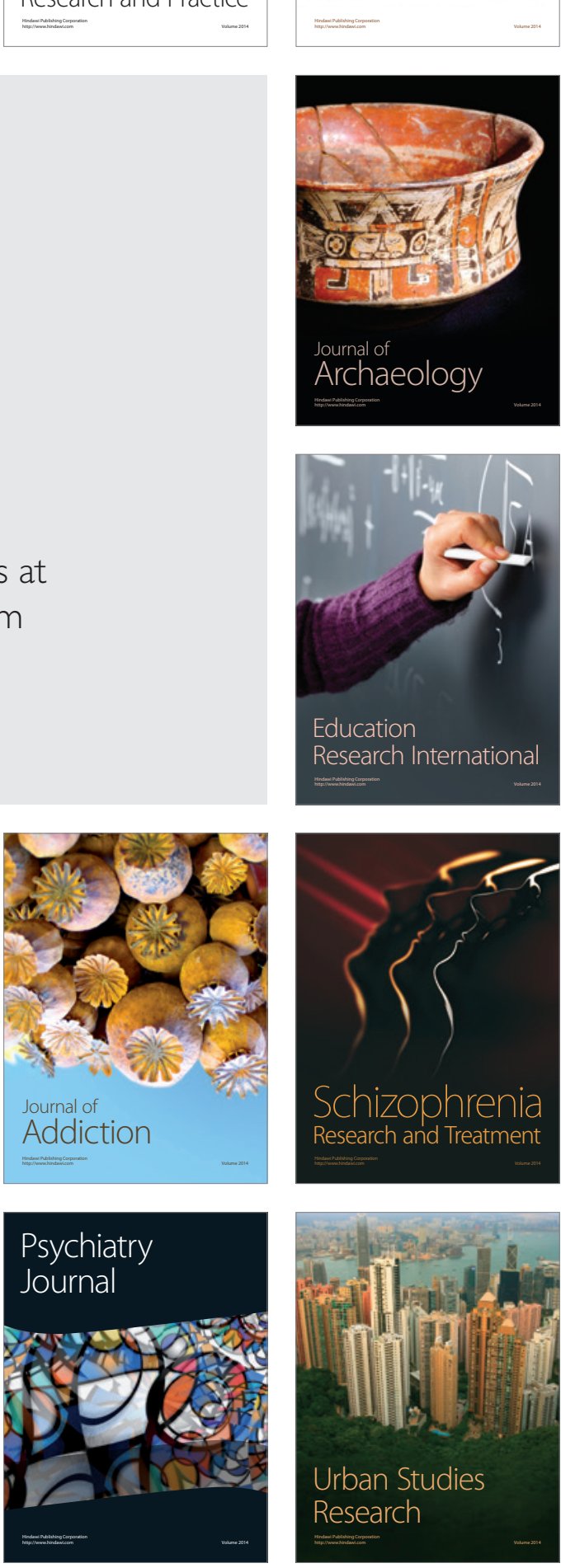